\title{
RESENHAS
}

DOI http://dx.doi.org/10.1590/0104-93132015v21n1p213

BIRMAN, Patrícia; LEITE, Márcia Pereira; MACHADO, Carly \& SÁ CARNEIRO, Sandra de. 2015. Dispositivos urbanos e trama dos viventes: ordens e resistências. Rio de Janeiro: Editora FGV. 504pp.

\section{Camila Pierobon}

Doutoranda em Ciências Sociais - PPCIS/UERJ Bolsista CNPq

Que formas de vida social, política, econômica emergem das cidades, em seus lugares mais precários? Quais agenciamentos e mediações são produzidos nas dobras entre legal e ilegal? Que dispositivos de ordens e resistências são operados pelos sujeitos no cotidiano? Como são produzidas as margens urbanas e que tipos de alteridades e fronteiras decorrem do contato entre os diferentes agentes atuantes nesses espaços? De que maneira subjetividades e moralidades são construídas nos interstícios entre violências e lutas por justiça, ilegibilidades das leis e discricionaridades de suas aplicações? Quais estratégias de visibilidades e invisibilidades são criadas pelos sujeitos nas situações e problemas específicos? Nos 20 capítulos que compõem o livro Dispositivos urbanos e trama dos viventes: ordens e resistências, estas questões são enfrentadas pelos autores com densidade etnográfica e potência analítica.
Inspiradas em alguns temas trabalhados por Foucault, o livro organizado por Patrícia Birman, Márcia Pereira Leite, Carly Machado e Sandra de Sá Carneiro tem como escopo problematizar questões relativas ao urbano sem a pretensão de resolvê-los. Inquietas com os embaralhamentos das racionalidades vigentes na vida social e os emaranhados de estratégias operados pelos sujeitos nas cidades contemporâneas, as organizadoras convidaram pesquisadores de várias instituições a apresentarem suas reflexões no colóquio realizado em 2011 na UERJ ante o seguinte desafio: apresentar, através do trabalho etnográfico, os jogos de poderes operados no cotidiano em suas diferentes escalas e transversalidades, os agenciamentos políticos, as lógicas de mercado, os mediadores no campo religioso e/ou das ONGs, os usos de recursos midiáticos, as reivindicações em torno de direitos, os processos de construções de identidades, de subjetividades e territorialidades, as formas de manutenção e atualização de violências. Por isso a ideia de dispositivos urbanos abre o livro, seguido de trama, que valoriza as interseções concretas exercidas pelos viventes.

Das discussões sugiram as quatro partes do livro: "Das tramas e dos dispositivos urbanos", abre a coletânea com textos teóricos, mas com ancoragem etnográfica, nos quais Michel Agier, 
Vera Telles e Michel Misse discutem suas atuais preocupações de pesquisa. "Entre o legal e ilegal: práticas e discursos sobre o urbano" foca no governo das populações pobres a partir das estratégias operadas pelos agentes nos interstícios entre legalidade e ilegalidade. A terceira parte, "Presos do lado de fora: periferias, quilombos, favelas e ocupações", discute os processos de produções identitárias e seus desdobramentos em questões territoriais, étnicas e/ou raciais, entretecidas com construções de políticas, fronteiras e alteridades. Na última parte, "Experiências de terror: revelação e ocultamento", a violência aparece como um importante dispositivo do ordenamento urbano, que envolve formas de medo e silenciamentos, subjetividades e moralidades, agenciamentos e lutas por justiça, visibilidades/invisibilidades.

Encorajada pela "Apresentação" de Luis Antonio Machado da Silva, proponho tecer outras "costuras" entre os textos. Enfatizo nesta resenha a presença de um ator que incorpora diferentes dispositivos presentes nas cidades contemporâneas e que, a meu ver, está no centro das discussões que tratam das gestões urbanas: o policial.

Polícia, importante agente das tramas urbanas que tangencia a vida ordinária daqueles que habitam as margens urbanas. Com o cruzamento dos textos, o policial aparece como uma figura capilar, quase impossível de se escapar, que coloca em funcionamento diversos dispositivos presentes nas cidades contemporâneas. Como um dos agentes na produção de fronteiras e territorialidades, o policial surge no texto de Michel Agier como aquele que evacua e destrói campos de refugiados ao incorporar a violência como força política do Estado. Seja nos campos da cidade grega de Patras, de Calais no norte da França ou de Dadaab no Quênia, esse personagem gere terri- torialidades, ora fixando fronteiras, ao impedir a passagem de algumas pessoas ou grupos, ora flexibilizando-as, quando autoriza certos acessos e proteções via pagamento de tributos.

Voltando os olhos para o Rio de Janeiro, o policial aparece como aquele que cumpre a ordem de expulsar quem contesta a ordem hegemônica da propriedade privada. Seja em favelas, seja em quilombos e ocupações, as questões habitacionais dos espaços valorizados da cidade são correntemente transformadas em problemas de polícia. Nos textos de Patrícia Birman e Jérôme Souty o policial é quem coloca o poder do Estado em ação, atuando como produtor de delinquência na cena das ocupações e como agente no processo de criminalização dos quilombos urbanos. A partir dos textos, podemos entender que política e Estado são operados através do exercício da força policial, que estabelece formas de autoridade, gestão e controle aos habitantes desses espaços.

Adriana Fernandes aponta em seu trabalho um regime de tensão no interior das ocupações de moradia quando se associa polícia e tráfico de drogas às possibilidades de violências e usurpações. Contudo, a autora capturou uma situação de conflitos e negociações envolvendo religiões, identidades, racializações, políticas públicas em uma ocupação popular e o Museu da Polícia Militar. Neste estariam "presas" estátuas de Orixás e alguns moradores mobilizaram estratégias para trazê-las ao imóvel, que seria transformado em um espaço da cultura negra.

No trabalho de Vera Telles e de Daniel Hirata, o policial opera fronteiras e territorialidades quando regula os territórios dos mercados populares. É ele quem controla oficialmente os trabalhadores ambulantes, fiscaliza suas autorizações para a venda de mercadorias, vistoria o local das negociações e, no limite, 
pode decidir se o vendedor está (ou não) dentro da legalidade. Como os trabalhos demonstram, o policial atua por meio do poder discricionário, próprio de suas atividades, que se soma à ilegibilidade das leis, suas brechas e alterações. Imbricado com mafiosos, traficantes de drogas e milicianos, o policial está no centro das relações de força e dos jogos de acordos e negociações que envolvem chantagens, compras de proteção e formas de extorsões que flexionam a aplicação das leis.

O policial também é um ator dos dispositivos de violência e terror nas cidades contemporâneas. A partir do adiamento de uma audiência judicial, que integra o julgamento de policiais que cometeram assassinatos, Adriana Vianna analisa os processos de construção de subjetividades na dolorosa espera dos familiares da vítima por uma nova audiência. O sofrimento de familiares, advindo da morte de um filho, se soma à figura fantasmagórica do policial que cometeu o assassinato e está livre, às possíveis violações que podem ocorrer sobre aqueles que demandam por justiça e o "tempo de espera", marcado por dor, desânimo, cansaço e pelas adversidades que impedem a reparação.

A questão da violência trabalhada por Juliana Farias está na aplicação dos "autos-de-resistência" que oficializam a morte de moradores de favelas e periferias. Essas mortes provocadas por policiais são contrapostas pelos familiares através dos exames de laudos cadavéricos, que muitas vezes apontam o contrário do que foi registrado como causa mortis. Neste complicado jogo de veridificação, Farias nos apresenta como familiares de vítimas constroem estratégias de visibilização dessas mortes, que variam entre a exposição pública e o trabalho artesanal de reunir provas da inocência da vítima e de sua execução. Em alguma medida, o trabalho de Amanda Dias resvala nestas questões quando o poeta Deley de Acari, um dos "intelectuais das margens" que a autora analisa, toma para si a tarefa de transmitir pedagogicamente a ideia de que os moradores de favelas têm o direito de denunciar as agressões arbitrárias realizadas pela polícia.

A discussão de Myrian Sepúlveda dos Santos se dá em torno da espetacularização das implosões de presídios e da invisibilização das violências em seu interior. O policial aparece em seu texto ora como ouvidoria da Polícia Militar, ora como aquele que pratica torturas e mortes no interior desses espaços. São eles, junto com agentes penitenciários, moradores dos arredores das prisões e familiares de presos que percebem, em seu cotidiano, as ambivalências de um sistema que se caracteriza pela violência, a tortura e o terror.

Carly Machado discute a polícia por meio do sofrimento daquele que produz violência. Inseridos em uma cartografia moral e em uma complexa política das emoções que classifica quem pode sofrer, o policial é correntemente colocado do lado dos "sem sentimentos". No entanto, quando Machado analisa a Tropa de Louvor do Ministério do Batalhão de Operações Especiais da Polícia Militar (banda gospel do Bope), o sofrimento aparece como construtor de moralidades e masculinidades, e sofrer significa suportar a morte para obter salvação, perdão e esperança. Como agente nos processos de construção de moralidades e masculinidades, o policial surge nos textos de Michel Misse e César Teixeira a partir das relações sociais que se desenrolam no contexto de "violência urbana". Importante ator na produção da sujeição criminal e presente nos discursos oficiais que separam quem está na "vida do crime" e quem tem uma "vida normal", o policial está inserido nas práticas de produção de subjetividades que se entrelaçam às ações 
religiosas e de ONGs, que mantêm como pano de fundo o espectro do bandido.

Outros dispositivos entram nas cenas urbanas através da figura do policial. O texto de Rafael Soares Gonçalves destaca como esse personagem está no centro da gestão de territórios associados à especulação imobiliária. A instalação de Unidades de Polícias Pacificadoras (UPPs) em algumas favelas do Rio de Janeiro é analisada pelo autor como parte de uma rede estratégica de valorização de territórios de favelas e seu entorno, envolvida nas dinâmicas dos mega eventos e no interior das lógicas de turismo. Como explorado por Bianca Freire-Medeiros, essa nova lógica de turismo incorpora formas de "turismo em favelas", exercidas naquelas que estão sob intervenção da Polícia Militar. Comparando favelas no Brasil e townships na África do Sul, a autora analisa as relações de poder no campo do turismo associadas à lógica do empreendedorismo local como possibilidade de os moradores de favela se tornarem responsáveis por seu próprio negócio.

No interior da lógica do mercado neoliberal, cada indivíduo deveria tornar-se empreendedor e criador de seu próprio capital. Como nos mostra Lia de Mattos Rocha, os "projetos sociais" direcionados a jovens moradores de favelas, realizados por ONGs, muitas delas em áreas que estão sob a guarda dos policiais das UPPs, atuam conjuntamente na repressão e na disciplinarização de corpos e moralidades. Dentre as ações policiais está o controle do espaço público, que acompanha as configurações dos mercados, funcionando como elemento moralizante no processo de classificação dos jovens que são "recuperáveis" e os "não recuperáveis". A pesquisa de Márcia Pereira Leite nos fala sobre a implantação dos postos de policiamento permanente das UPPs e como essa nova forma de policiamento de favelas produz como efeito a gestão da vida local e a administração dos conflitos. No argumento da autora, o policiamento de permanência tem modificado as dinâmicas de violências, a lógica da guerra, as formas de segregação e as escalas de cidadania.

O repertório gramatical operado por moradores de condomínios fechados na zona oeste do Rio de Janeiro aciona a figura do policial na construção de gradações de moralidades, cidadanias e humanidades. Jussara Freire analisa como membros das camadas médias urbanas consideram legítimas a intervenção policial em favelas e a permanência da polícia nesses espaços associados ao crime e à criminalidade. No entanto, o policial não é bem vindo nos condomínios fechados, cuja presença contaminaria moralmente aquele espaço dos "contribuintes" considerados por si mesmos "cidadãos de primeira categoria".

Os textos de Véronique Boyer e José Maurício Arruti são aqueles em que a figura do policial não está presente. No entanto, podemos tecer outras "costuras" através dos processos de produção de territorialidades. Boyer está preocupada com os regimes de diferenciação e os registros de identificação dos quilombos na Amazônia. Para a autora, o estado aciona categorias jurídicas que pressupõem a identidade diferenciada dessas pessoas e, assim, cria novas fronteiras entre grupos, territórios e identificações. Arruti discute os dispositivos territoriais e populacionais relacionados aos quilombos urbanos, analisando seu repertório discursivo. Em seu trabalho, Arruti nos apresenta como certos agenciamentos discursivos produzem uma diversidade de sentidos que não podem ser dissociados de suas bases históricas e sociais.

Certamente o caminho escolhido para o cruzamento dos textos não é o único possível. Ficam guardadas para os futuros 
leitores novas "costuras" entre os trabalhos que enriquecerão os debates sobre os dispositivos urbanos vigentes nas cidades contemporâneas. Antes de finalizar, gostaria de destacar a relevância ética e política dos textos, que fazem circular visões minoritárias sobre as cidades e sobre as violências presentes nas formas de governar as populações pobres.

DOI http://dx.doi.org/10.1590/0104-93132015v21n1p217

FRANÇOZO, Mariana de Campos. 2014. De Olinda a Holanda: o gabinete de curiosidades de Nassau. Campinas, SP: Editora da Unicamp. 287 pp.

\section{Rita de Cássia M. Santos}

Doutoranda do PPGAS/MN/UFRJ

A problematização da coleção de Maurício de Nassau, formada durante seus anos de administração da possessão holandesa no Nordeste do Brasil (1637-1644), é o pano de fundo no qual Mariana Françozo tece seu primoroso livro. Busca a autora reestabelecer as diferentes temporalidades da coleção em seus processos de formação, circulação e dispersão, apostando que o desenrolar dessa imbricada rede a guiará às conexões atlânticas que, no limite, identificam o colecionismo do século XVII aos jogos políticos do circuito colonial. Ao abordar o processo de formação e circulação da coleção de Nassau, Françozo permite entrever ainda a dinâmica de produção de saberes sobre o Brasil nos Países Baixos da época Moderna, observada e analisada a partir das práticas sociais.

Desdobramento de sua tese de doutoramento em antropologia pela Unicamp, sob supervisão do ilustre professor John Monteiro, este trabalho combina uma aguçada pesquisa histórica com uma criativa linha de investigação antropo- lógica, que pode ser apreciada a partir de três eixos.

Em um primeiro eixo, o livro apresenta os modos pelos quais o colecionismo do século XVII imbrica-se com as rotas comerciais e de dominação colonial. Os objetos colecionáveis confundem-se com os itens de comércio, e as pessoas que os trocam, com os agentes coloniais. Os casos analisados do percurso da bacia de prata e dos chapéus de Castor, trocados entre Nassau e representantes do Congo, apresentam as dinâmicas coloniais que punham em contato áreas tão distantes quanto Holanda, África, Peru e Pernambuco e que fortaleciam o comércio de açúcar e de escravos. Ainda sobre a bacia de prata, a investigação da sua origem remonta ao Peru. Segundo a autora, a bacia deve ter seguido para a África por meio de comerciantes, lá utilizada para compra de escravos e posteriormente presenteada a Nassau. As coleções, como demonstra a autora, não são fixas e perenes, ao contrário, o seu valor reside justamente no movimento. As trocas, as permutas, as inclusões eram frequentes e justificavam a sua importância.

Ainda nessa direção, Françozo analisa um conjunto de instigantes questões postas a partir da aplicação do conceito de dádiva às práticas colecionistas do século XVII. Elaborado por Marcel Mauss, o conceito de dádiva buscava compreender as implicações do sistema de trocas na conformação das relações pessoais, dito de outro modo, como a troca de objetos converte-se em laços pessoais. Aqui, Françozo o utiliza para compreender os sentidos e os significados das múltiplas doações que envolvem a formação da coleção e sua posterior dispersão no contexto europeu e americano, entre europeus e populações autóctones. Como resultado, percebemos os diferentes caminhos pelos quais Nassau, a partir de sua coleção, constrói um nome de prestígio, o bem 